
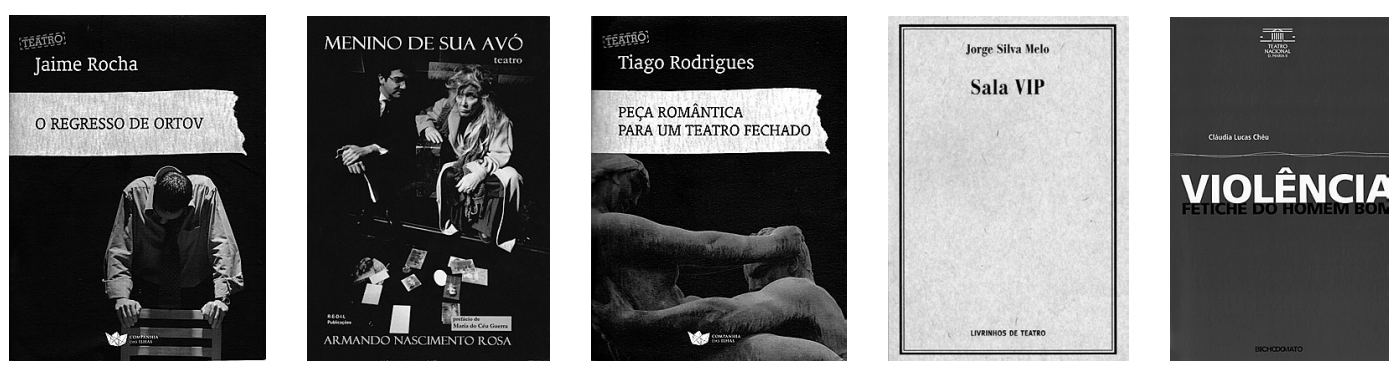

\title{
Publicações de teatro em 2013
}

\author{
Lista compilada por Sebastiana Fadda
}

Peças originais (ou volumes de peças) em primeira edição

CAMPIÃO, Luis, Nossa Senhora de Açoteia, vencedor do Prémio Luso-Brasileiro de Dramaturgia António José da Silva 2012, Lisboa, Chiado Editora, 2013.

CHÉU, Cláudia Lucas, Violência: Fetiche do homem bom [seguido de Spirale de Jouissance: Círculo onanista / Bank bank, You're dead? /Europa, Ich Liebe Dich: Guião de uma discoperformance], Lisboa, Teatro Nacional D. Maria II - Bicho do Mato, 2013.

COELHO, Rui Pina, Já passaram quantos anos, perguntou ele e outros textos (A irrisão das flores / Fall collection /Ainda assim), Vila Nova de Famalicão, Húmus / Círculo de Cultura Teatral / Teatro Experimental do Porto, Colecção Teatro não é literatura, 2013.

--, Ás vezes quase me acontecem coisas boas quando me ponho a falar sozinho, Lajes do Pico, Companhia das Illhas, Colecção Azulcobalto, 2013.

CORREIA, Natália, Sucubina ou a teoria do chapéu, org. Ângela de Almeida, Clayton Santos Guimarães e Cristina Marinho, Porto, Centro de Estudos Teatrais da Universidade do Porto / Casa dos Açores do Norte, 2013.

CRUZ, Afonso, 0 cultivo de flores de plástico, Carnaxide, Editora Objectiva / Algaguara, 2013.

GOUVEIA, José Fialho, Amarrada à tua mão, Galveias, Teatro da Terra, 2013.

MELO, Jorge Silva, Sala Vip, Lisboa, Artistas Unidos / Livros Cotovia, Livrinhos de Teatro n. ${ }^{\circ}$ 76, 2013.

MENDONÇA, José Tolentino, 0 estado do bosque, Lisboa, Assírio \&t Alvim, 2013.

MESTRE, Luis, Do precipício tempestuoso de Ricardo III, prefácio de António Durães, Vila Nova de Famalicão, Húmus, 2013.

MILAGRE, Nuno, Meias-irmãs, Galveias, Teatro da Terra, 2013.

MIRANDA, Francisco de Sá, Comédias, edição de José Camões e Thomas F. Earle, Lisboa, Imprensa NacionalCasa da Moeda, Biblioteca de Autores Portugueses, 2013.

MONGE, João, Chão de água, Galveias, Teatro da Terra, 2013.

NEVES-NEVES, Ricardo, A porta fechou-se e a casa era pequena, Lajes do Pico, Companhia das Ilhas, Colecção Azulcobalto, 2013.
PESSOA, Fernando, Fausto, edição de Teresa Sobral Cunha prefácio de Eduardo Lourenço, Lisboa, Relógio d'Água, 2013.

REBELLO, Luiz Francisco, Teatro naturalista, Lisboa, Imprensa Nacional-Casa da Moeda, Biblioteca de Autores Portugueses, 2013.

REDOL, Alves, Teatro: Textos publicados e inéditos, coordenação, introdução e notas de Miguel Falcão, Lisboa, Imprensa Nacional-Casa da Comédia, Biblioteca de Autores Portugueses, 2013.

ROCHA, Jaime, 0 regresso de Ortov, Lajes do Pico, Companhia das Ilhas, Colecção Azulcobalto, 2013.

RODRIGUES, Tiago, Peça romântica para um teatro fechado, Lajes do Pico, Companhia das Ilhas, Colecção Azulcobalto, 2013.

--, Três dedos abaixo do joelho / Tristeza e alegria na vida das girafas / Coro dos amantes, posfácio de Fernando Matos Oliveira, Coimbra, Imprensa da Univ. de Coimbra, 2013.

ROSA, Armando Nascimento, Menino de sua avó, prefácio de Maria do Céu Guerra, Lisboa, Redil Publicações, 2013.

SÉRIO, Mário, Trilogia dos amores malditos [Sirius / Jogos de devação/Juízo final], Lisboa, Cavalo de Ferro, 2013.

\section{Traduções}

BECKET, Samuel, Ah, os dias felizes, trad. Alexandra Moreira da Silva; Não eu, trad. Paulo Eduardo Carvalho, Porto, Húmus \& TNSJ, 2013.

COWARD, Noel, Vidas intimas/Vida de artista, trad. Migue Esteves Cardoso (Vidas intimas) e José Maria Vieira Mendes (Vida de artista), Lisboa, Artistas Unidos / Livros Cotovia, Livrinhos de Teatro n. 73, 2013.

--, Vórtice/Espírito alegre, trad. Pedro Marques a partir da versão de José Palla e Carmo (Vórtice) José Maria Vieira Mendes (Espírito alegre), Lisboa, Artistas Unidos / Livros Cotovia, Livrinhos de Teatro n. 74, 2013.

PIRANDELLO, Luigi, Tu vê lá, Giacomino!/ Como tu queiras / Não se sabe como, trad. Jorge Silva Melo (Tu vê lá, Giacomino! / Como tu queiras) e Costa Ferreira, ver. por Ana Bigotte Vieira e Clelia Betinni, com a colaboração de Miguel Castro Caldas (Não se sabe 


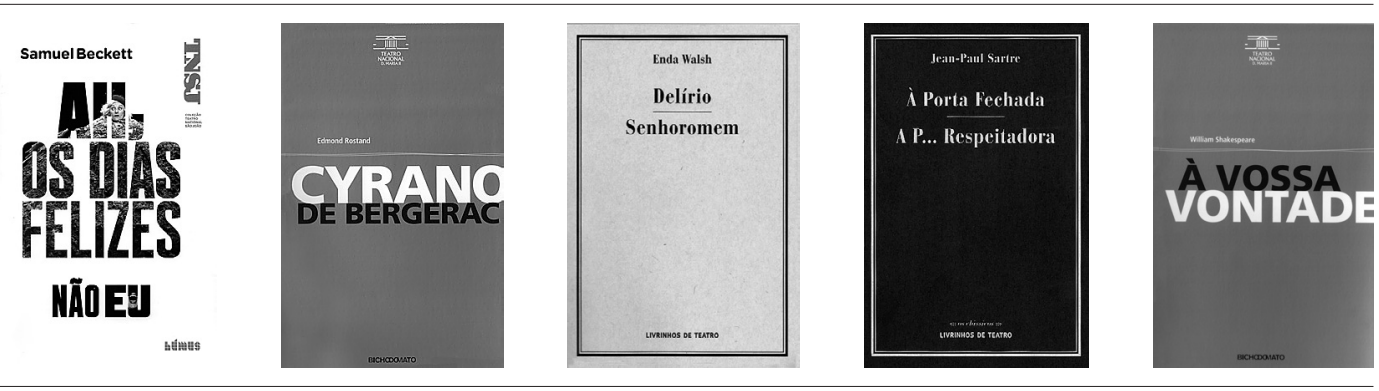

como), Lisboa, Artistas Unidos / Livros Cotovia, Livrinhos de Teatro n. ${ }^{\circ}$ 71, 2013.

ROSTAND, Edmond, Cyrano de Bergerac, trad. Nuno Júdice, Lisboa, Teatro Nacional D. Maria II - Bicho do Mato, 2013.

SARTRE, Jean-Paul, À porta fechada / A p... respeitadora, trad. Virgínia e Jacinto Ramos e Regina Guimaraes, Lisboa, Artistas Unidos / Livros Cotovia, Livrinhos de Teatro n. ${ }^{\circ}$ 70, 2013.

SHAKESPEARE, William, $\dot{A}$ vossa vontade, trad. Fernando Villas-Boas, Lisboa, Teatro Nacional D. Maria II - Bicho do Mato, 2013.

--, Henrique IV, Parte II, tradução, introdução e notas de Gualter Cunha, Lisboa, Relógio d'Água, Projecto Shakespeare, 2013.

--, Romeu e Julieta, tradução, introdução e notas de Filomena Vasconcelos, Lisboa, Relógio d'Água, Projecto Shakespeare, 2013.

SPREGELBURD, Rafael, A inapetência / A extravagância / A modéstia, trad. Alexandra Moreira da Silva e Guillermo Heras, Lisboa, Artistas Unidos / Livros Cotovia, Livrinhos de Teatro n. ${ }^{\circ}$ 78, 2013.

TABORI, George, Mein kampf / 0 branco judeu e o pele vermelha / Os canibais, trad. António Conde e José Maria Vieira Mendes (Mein kampf) e José Maria Vieira Mendes (O branco judeu e o pele vermelha / Os canibais), Lisboa, Artistas Unidos / Livros Cotovia, Livrinhos de Teatro n. ${ }^{\circ}$ 69, 2013.

--, Coragem de mãe / Variações Goldberg, trad. António Conde (Coragem de mãe) e Maria Antónia Amarante (Variações Goldberg), Lisboa, Artistas Unidos / Livros Cotovia, Livrinhos de Teatro n. ${ }^{77,} 2013$.

VALLE-INCLÁN, Ramón del, Retábulo da avareza, luxúria e morte, trad. Jorge Silva Melo e Norberto Ávila, Lisboa, Artistas Unidos / Livros Cotovia, Livrinhos de Teatro n. 67,2013

--, Ramón del, Divinas palavras, trad. Jorge Silva Melo, Lisboa, Artistas Unidos / Livros Cotovia, Livrinhos de Teatro n. ${ }^{\circ}$ 68, 2013.

WADJI, Mouawad, O sangue das promessas: Céus/Florestas / Litoral / Incêndios, trad. Manuela Torres, revisão Madalena Alfaia, Lisboa, Artistas Unidos / Livros Cotovia, Livrinhos de Teatro n. ${ }^{\circ}$ 72, 2013.

WALSH, Enda, Delírio/Senhoromem, trad. Nuno Ventura Barbosa, Lisboa, Artistas Unidos / Livros Cotovia, Livrinhos de Teatro n. 75, 2013.

WEDEKIND, Frank, 0 despertar da Primavera, trad., prefácio e notas de João Barrento, Vila Nova de Famalicão / Porto, Húmus / Teatro Nacional São João, Colecção Teatro Nacional São João, 2013.

\section{Traduções em reedição}

BECKETT, Samuel, À espera de Godot, trad. José Maria Vieira Mendes, Lisboa, Livros Cotovia, 2013, 5a ed.

SHAKESPEARE, William, Henrique IV, Parte I, tradução, introdução e notas de Gualter Cunha, Lisboa, Relógio d'Água, Projecto Shakespeare, 2013, 2a ed.

SÉNECA, Medeia, tradução do latim, introdução e notas de Ana Alexandra Alves de Sousa, Coimbra, Imprensa da Universidade de Coimbra, Autores Gregos e Latinos - Textos, 2013, 3a ed.

\section{Estudos / Documentos}

AA.W., Teatro como quem respira: Homenagem a Armando Caldas, Oeiras, CMO, 2013.

ANDRADE, Cláudia, Coro: Corpo colectivo e espaço poético. Interseções entre o teatro grego antigo e o teatro contemporâneo, Coimbra, Imprensa da Universidade, 2013.

CASTANHEIRA, José Manuel, José Manuel Castanheira: Cenografia, com textos de George Banu, Marcel Freydefont e João Carneiro, Casal de Cambra, Caleidoscópio, 2013.

CATALÃO, Rui / GANDRA, Tiago, Ingredientes do mundo perfeito, s.l., Mundo Perfeito, 2013.

DOLORES, Carmen, No palco da memória, Lisboa, Sextante, 2013.

DUARTE, Teresa, Teatro para crianças, teatro para todos: Um percurso histórico do teatro para a infância em Portugal, s.l., Editorial do Ministério da Educação e Ciência, 2013.

LOPES, Maria Virgílio Cambraia, Rafael Bordalo Pinheiro: Imagens e memórias do teatro, Lisboa, Imprensa Nacional-Casa da Moeda, Colecção Arte e Artistas, 2013.

REIS, Luciano, João d'Ávila: Do teatro à poesia, Lisboa, Fonte da palavra, 2013.

SASPORTES, José, A quinta musa: Imagens da história da dança, Lisboa, Bizâncio, 2013.

SERÔDIO, Maria Helena, Joaquim Benite: Desafiou Próspero... e inscreveu o mundo no seu teatro, Almada, Companhia de Teatro de Almada, 2013.

--, Financiar o teatro em Portugal: A actuação da Fundação Calouste Gulbenkian (1959-1999), posfácio de Maria João Brilhante, Lisboa, BonD / Centro de Estudos de Teatro, 2013. 

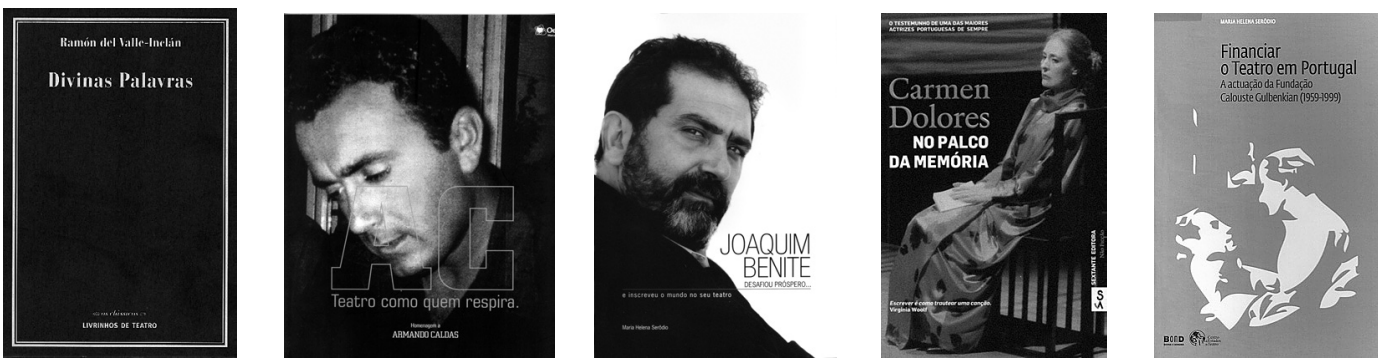

\section{Publicações periódicas}

Cine Qua Non: Bilingual Arts Magazine / Music, dance, theatre, visual arts, literature, cinema, n. 7 (Spring / Fall 2013). Dir. Ana Luisa Valdeira da Silva, Lisboa, Centro de Estudos Anglísticos da Universidade de Lisboa.

Sinais de cena, n.os 19 (Junho 2013) e 20 (Dezembro 2013) dir. Maria Helena Serôdio, Lisboa, Associação Portuguesa de Críticos de Teatro \& Centro de Estudos de Teatro, Húmus.

\section{Adenda à lista publicada na Sinais de cena n. ${ }^{\circ} 19$ (2012)}

BARKER, Howard, Devagar, trad. Constança Carvalho Homem, Coimbra, Temas Originais / As Boas Raparigas, 2012. [Tradução]

HADJADY, Fabrice, Job ou a tortura pelos amigos, trad. Carlos A. Moreira Azevedo, Vila Nova de Gaia, Contra Cena, Teatro, 2012. [Tradução]

SCHNITZLER, Arthur, A ronda. Dez diálogos, trad. Manuel Resende, Lisboa, Relógio d'Água, 2012. [Tradução]

MASCOLO, Anna, Celebrar a dança em dias do meu tempo, Lisboa, Transversal, 2012. [Estudos / documentos]

\section{Adenda à lista publicada na Sinais de cena n. ${ }^{\circ} 17$ (2011)}

ÁVILA, Norberto, O bobo, Lisboa, Imprensa Nacional-Casa da Moeda / Sociedade Portuguesa de Autores, 2011. [Peça original]

BARKER, Howard, Mulheres profundas / Animais superficiais, trad. Paulo Eduardo Carvalho, Coimbra, Temas Originais / As Boas Raparigas, 2011. [Tradução]

HERBON, Rui, 0 álbum de familia, Lisboa, Imprensa Nacional-Casa da Moeda / Sociedade Portuguesa de Autores, 2011. [Peça original]

RODRIGUES, Urbano Tavares, As torres millenárias, Lisboa, Imprensa Nacional-Casa da Moeda / Sociedade Portuguesa de Autores, 2011. [Peça em reedição]

SANTIAGO, Carlos, Abraço de ferro, s.l., AGAL (Associaçom Galega de Lingua) / Através Editora, 2011. [Peça original]

SÉNECA, Medeia, tradução do latim, introdução e notas de Ana Alexandra Alves de Sousa, Coimbra, Imprensa da Universidade de Coimbra, Autores Gregos e Latinos - Textos, 2011. [Tradução]
THIVAT, Patricia-Laure, Cultura e emigração: 0 teatro alemão no exílio nos E.U.A.: 1933-1950, pref. da ed. original de Michael Wrner, trad. Rita Valente, Évora, Editora Licorne / Colecção B, 2011. [Estudos / documentos]

Adenda à lista publicada na Sinais de cena n. ${ }^{\circ} 15$ (2010)

BARKER, Howard, As possibilidades, trad. Paulo Eduardo Carvalho, Coimbra, Temas Originais / As Boas Raparigas, 2010. [Tradução]

BARKER, Howard, (Tio) Vânia, trad. Paulo Eduardo Carvalho, Coimbra, Temas Originais / As Boas Raparigas, 2010. [Tradução]

GALHÓS, Claudia, Pina Bausch: Ensaio biográfico, pref. Jorge Salavisa, Lisboa, D. Quixote, 2010. [Estudos / documentos]

\section{Adenda à lista publicada na Sinais de cena} n. ${ }^{\circ} 11$ (2008)

\section{CRUZ, Duarte Ivo, De volta aos teatros: 0 contributo} mecenático da Tabaqueira, Civilização Editora, 2008. [Estudos / documentos] 